\title{
PENGEMBANGAN BUSSINESS INTELEGENCE (BI) UNTUK PERUSAHAAN DALAM MEMBANGUN SOLUSI BISNIS BERBASIS OPEN SOURCE
}

\author{
Ferry Sudarto ${ }^{1}$ \\ Diah Aryani ${ }^{2}$ \\ Yulianto $^{3}$ \\ E-mail :_erry.sudarto@raharja.info, diah.aryani@raharja.info, vulianto@raharja.info
}

\begin{abstract}
ABSTRAK
Saat ini penggunaan Information Technology sebagai alat bantu dalam kegiatan bisnis sudah menjadi kebutuhan mutlak. Hal ini dikarenakan adanya kebutuhan dari organisasi tersebut untuk meningkatkan kemampuannya dalam menganalisis masalah-masalah yang dihadapinya serta dalam pengambilan keputusan. Namun sebenarnya hal ini hanyalah sebagian kecil dari pemanfaatan IT dalam mendukung kegiatan bisnis. Peranan IT dapat ditingkatkan dengan merancang dan mengimplementasikan suatu sistem yang dapat mengekstrak dan mengubah informasi bisnis dari data-data operasional yang ada sehingga pada akhirnya dapat memberikan dukungan terhadap keputusan-keputusan bisnis. Business Intelligence (BI) merupakan salah satu bentuk implementasi yang mampu menjawab kebutuhan di atas. Secara ringkas, BI dapat diartikan sebagai pengetahuan yang didapatkan dari hasil analisis data yang diperoleh dari kegiatan (usaha) suatu organisasi. Salah satu tool untuk implementasi BI berbasis open source adalah Pentaho. Pentaho merupakan kumpulan aplikasi BI yang berkembang dengan pesat dan bersifat free open source software (FOSS).
\end{abstract}

Kata kunci: Information Technology (IT), business intelligence, free open source software (FOSS)

\section{ABSTRACT}

Today the use of Information Technology as a tool in business activities has become an absolute necessity. This is because the needs of the organization to improve its ability to analyze the problems faced in the decision. But in fact this is just a small part of the use of IT in support of business activities. The role of IT can be enhanced by designing and implementing a system that can extract and transform business information from operational data exist that could ultimately provide support for business decisions. Business Intelligence (BI) is one form of implementation that address the needs above. In summary, BI can be defined as the knowledge gained from the analysis of data obtained from the activity (business) organizations. One tool for BI implementation is based on open source Pentaho. Pentaho BI suite of applications is growing rapidly and is free open source software (FOSS).

Keywords: Information technology business intelligence, free open source software (FOSS)

\section{PENDAHULUAN}

Dewasa ini penggunaan teknologi informasi yang diintegrasikan dengan proses pekerjaan di suatu organisasi sudah menjadi kebutuhan mutlak. Ketersediaan data dan informasi yang lengkap, benar dan tepat sudah menjadi kebutuhan pokok bagi kelangsungan hidup suatu organisasi. Business Intelligence (BI) merupakan salah satu bentuk implementasi yang mampu menjawab kebutuhan di atas. BI telah banyak 
digunakan oleh organisasi- organisasi dalam mengelola data dan informasi sampai dengan dukungan pengambilan keputusan. Business Intelligence merupakan kategori yang umum digunakan untuk aplikasi dan teknologi untuk mengumpulkan, menyimpan, menganalisa, dan menyediakan akses pada data agar dapat membantu pengguna dari kalangan perusahaan agar dapat mengambil keputusan dengan lebih baik dan tepat [1].

Penerapan BI secara tepat untuk suatu sistem yang sudah ada selalu memerlukan biaya yang besar, baik itu berupa dana, waktu, maupun sumber daya manusia. Di sisi lain, menurut beberapa hasil studi dan riset, pembangunan BI juga memiliki risiko yang cukup besar untuk mengalami kegagalan (tidak sesuai dengan kebutuhan organisasi). Risiko ini akan terjadi jika pembangunan BI tersebut tidak direncanakan secara cermat.

Pengimplementasian aplikasi Business Intelligence berbasis Open Source yang terintegrasi dengan aplikasi manajemen seperti merupakan salah satu solusi yang bisa dipakai untuk mengatasi keterbatasan kemampuan manajemen dalam internal suatu perusahaan. Pentaho adalah free open source software (FOSS) BI yang tidak hanya menyediakan aplikasi BI, namun menyediakan platform untuk membangun solusi bisnis dengan aplikasi BI yang dibentuk. Dengan Pentaho seluruh data yang dianalisa akan diberikan secara garis besar melalui tiga fungsi utama, yakni pembuatan analisa, pembuatan laporan dan penyediaan beberapa jenis dashboard. Besar cakupan analisa dibatasi oleh kebutuhan perusahaan yang dalam hal ini berkaitan dengan proses keuangan (Finance), penjualan (Penjualan), pembelian (Purchase), konsumen (Konsumen ), dan proses produksi (Manufaktur).

\section{METODOLOGI PENELITIAN}

Dalam membangun dan mengimplementasikan BI terdapat 3 (tiga) pendekatan yang bisa digunakan antara lain:

- Top-down Approach
Pendekatan top-down sangat tepat bagi suatu organisasi yang akan membangun BI dimana pada waktu yang bersamaan organisasi tersebut juga sedang melakukan perubahan proses kerja (Business Process re-engineering) secara menyeluruh di seluruh aspek organisasi. Pada pendekatan ini, kerangka data warehouse secara menyeluruh (enterprise data warehouse) harus disusun terlebih, baru kemudian diikuti oleh data warehouse departemental (data mart).

- Bottom-up Approach

Kebalikan dengan pendekatan sebelumnya, dalam pendekatan bottomup BI yang disusun justru dari tingkat departemental (departemental data warehouse), baru Kemudian diintegrasikan menjadi data warehouse organisasi secara keseluruhan. Pendekatan ini sangat tepat bagi kebutuhan suatu organisasi yang memprioritaskan pembangunan BI di suatu departemen terlebih dahulu. Kemudian setelah sukses di departemen tersebut akan dilanjutkan ke departemen lainnya.

- Practical Approoch

Pendekatan ini mengkombinasikan ke dua pendekatan sebelumnya untuk mendapat kelebihannya.

\section{HASIL DAN PEMBAHASAN}

Pengertian Business Intelligence

Business Intelligence diperkenalkan pertama kali pada tahun 1989 dan oleh Howard Dresner dari lembaga riset Gartner Group. Menurutnya, Business Intelligence adalah rangkaian aplikasi dan teknologi untuk mengumpulkan, menyimpan, menganalisis, dan menyuguhkan akses data untuk membantu petinggi perusahaan (management executive) dalam pengambilan keputusan. BI merupakan sistem pendukung pengambilan keputusan yang berbasiskan data-data [2] BI 
mampu memberikan keunggulan kompetitif (competitive advantage) untuk perusahaan melalui pemanfaatan data-data, informasi, dan pengetahuan (knowledge) yang dimiliki oleh perusahaan tersebut sebagai bahan baku dalam proses pengambilan keputusan.

BI saat ini dianalogikan sebagai supply chain informasi. Data didistribusikan dari database operasional secara periodic dengan melewati tahapan ekstraksi, pemberisan, integrasi, dan transformasi yang kemudian dimasukkan ke dalam sebuah data warehouse. Selanjutnya, data yang ada di data warehouse akan dianalisis dengan cara diquery oleh aplikasi analisis seperti OLAP atau Data Mining.

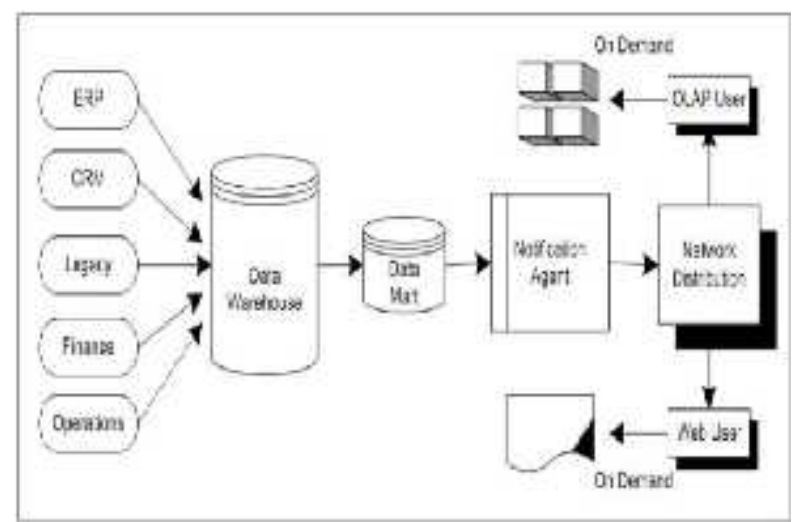

Gambar 1. Arsitektur Business Inteligence

Salah satu ciri khas arsitektur BI diatas terletak pada data warehouse. Data diekstraksi dari sistem operasional dan didistribusikan dengan teknologi yang ada. Data yang spesifik yang dibutuhkan untuk BI akan di-download menuju data mart yang digunakan oleh pihak perencanaan dan pihak eksekutif. Output dari BI berupa hasil analisis dari OLAP ataupun teknologi analisis data lainnya. Output dari BI bisa berupa berbagai macam form seperti laporan ataupun respon dari permintaan data yang spesifik [3].

\section{LITERATUR REVIEW}

Tabel 1 Penggolongan Literatur Review berdasarkan Klasifikasi Penelitian dan Metode Pastisipasi

\begin{tabular}{|c|c|c|c|}
\hline $\begin{array}{c}\text { Classificati } \\
\text { on }\end{array}$ & Example & Method & $\begin{array}{c}\text { Referen } \\
\text { ce }\end{array}$ \\
\hline $\begin{array}{c}\text { Theory } \\
\text { Building }\end{array}$ & $\begin{array}{l}\text { Evaluasi } \\
\text { Teknik } \\
\text { Optimalisa } \\
\text { si Proses } \\
\text { ETL dan } \\
\text { Skema } \\
\text { Data } \\
\text { Warehouse } \\
\text { untuk } \\
\text { Mendukun } \\
\text { g Tactical } \\
\text { Business } \\
\text { Intelligenc } \\
e\end{array}$ & $\begin{array}{c}\text { Kombi } \\
\text { nasi }\end{array}$ & $\begin{array}{l}\text { Karina } \\
\text { Novita } \\
\text { Suryani } \\
\& \quad I r . \\
\text { Hira } \\
\text { Laksmi } \\
\text { wati } \\
\text { Zoro, } \\
\text { M.Sc. } \\
\text { (2012) }\end{array}$ \\
\hline Field Study & $\begin{array}{l}\text { Implement } \\
\text { asi olap } \\
\text { dan } \\
\text { reporting } \\
\text { services } \\
\text { sebagai } \\
\text { Bagian } \\
\text { proses } \\
\text { business } \\
\text { intelligenc } \\
e\end{array}$ & $\begin{array}{c}\text { Kombi } \\
\text { nasi }\end{array}$ & $\begin{array}{l}\text { Kusnaw } \\
\text { i (2005) }\end{array}$ \\
\hline $\begin{array}{c}\text { Field } \\
\text { Experiment }\end{array}$ & $\begin{array}{l}\text { Perancang } \\
\text { an e- } \\
\text { business } \\
\text { "Business } \\
\text { Intelligenc } \\
\text { e" }\end{array}$ & TIK & $\begin{array}{c}\text { Noverin } \\
\text { o Rifai } \\
\& \\
\text { Kharizt } \\
\text { Attria } \\
\text { Gupta } \\
\text { (2004) }\end{array}$ \\
\hline $\begin{array}{c}\text { System } \\
\text { Developme } \\
n t\end{array}$ & $\begin{array}{l}\text { Pembangu } \\
\text { nan } \\
\text { aplikasi } \\
\text { bisnis } \\
\text { intelijen } \\
\text { berorienta } \\
\text { si servis }\end{array}$ & $\begin{array}{c}\text { Kombi } \\
\text { nasi }\end{array}$ & $\begin{array}{l}\text { Innarca } \\
\text { ya } \\
\text { Nadiar } \\
\text { Krisanti } \\
\text { Nasutio } \\
\text { n, } \\
\text { Riyanar }\end{array}$ \\
\hline
\end{tabular}




\begin{tabular}{|c|c|c|c|}
\hline & $\begin{array}{l}\text { pada } \\
\text { enterprise } \\
\text { resource } \\
\text { planning } \\
\text { dengan } \\
\text { pentaho } \\
\text { berplatfor } \\
\text { m java } \\
\end{array}$ & & $\begin{array}{l}\text { to } \\
\text { Sarno, } \\
\& \text { Dwi } \\
\text { Sunaryo } \\
\text { no } \\
(2007)\end{array}$ \\
\hline Field Study & $\begin{array}{l}\text { Business } \\
\text { Intelligenc } \\
\text { e in } \\
\text { College: A } \\
\text { Teaching } \\
\text { Case with } \\
\text { Real Life } \\
\text { Puzzles }\end{array}$ & $\begin{array}{c}\text { Kombi } \\
\text { nasi }\end{array}$ & $\begin{array}{l}\text { Wanda } \\
\text { Presthu } \\
\text { s and } \\
\text { Bendik } \\
\text { Bygstad } \\
(2012)\end{array}$ \\
\hline
\end{tabular}

\section{Tahapan Dalam Mengembangkan BI}

Dalam mengembangkan BI setidaknya terdapat tahapan-tahapan yang harus dilaksanakan untuk memastikan agar upaya pengembangan BI akan mencapai hasil yang maksimal [9] diantaranya:

a. Tahap Perencanaan Proyek (Project

\section{Planning)}

Pada tahapan ini harus dapat dijelaskan apa yang menjadi tujuan utama dari proyek BI, ekspektasi (harapan) yang diinginkan, dukungan formal dari Pimpinan organisasi yang bersangkutan, serta capaian-capaian (milestone) yang akan dituju.

b. Tahap Analisis Kebutuhan (Requirement Analysis)

Pada tahap ini harus sudah teridentifikasi kebutuhan pengembangan BI secara detail. Hal ini dapat dilakukan dengan menyusun dan mengumpulkan information package untuk semua subjek informasi yang akan ada dalam data warehouse. Fungsi information package adalah :

- Mendefinisikan subjek area dan ukuran pekerjaan (business process) utama
- Menentukan bagaimana data akan disajikan dan diakses

- Menentukan bagaimana pengguna akan melakukan agregasi atau roll up

- Menentukan kuantitas data untuk analisis atau query

- Menaksir ukuran data warehouse \& frekuensi data refreshing

- Memastikan bagaimana informasi akan di-package

c. Tahap Desain dan Konstruksi (Design and Construction)

Pada tahap ini harus telah tersusun arsitektur dan infrastruktur yang diinginkan dari desain BI, yang akan mencakup 3 (tiga) bagian utama yaitu :

\section{- Data Acquisition}

Bagian ini terkait dengan upaya mengekstraksi data dari sumber-sumber data, dan upaya memindahkan data yang sudah diekstrak tersebut ke staging area (tempat dimana semua data ekstraksi diletakkan bersamasama)

- Data Storage

Bagian ini terkait dengan upaya loading data dari staging area ke data warehouse repository (berupa relational data base)

- Information Delivery

Bagian ini terkait dengan upaya menyediakan user interface yang akan menghubungkan pengguna dengan data warehouse. Jenisnya dapat berupa OLAP, data mining, maupun report/query.

d. Tahap Implementasi (Deployment)

Pada tahap ini, pengembangan BI yang telah dilakukan pada tahap-tahap sebelumnya harus sudah dapat dites penggunaannya serta kemudian diujicoba apakah sudah memenuhi tujuan ditandai dengan telah dilaksanakannya user acceptance test (UAT) dan user telah memahami bagaimana menggunakan sistem tersebut dengan tepat.

e. Tahap Pemeliharaan (Maintenance) 
Kebutuhan informasi yang dibutuhkan organisasi akan terus berkembang. Untuk itu, sistem BI yang telah diimplementasikan mungkin saja memerlukan perkembangan lebih lanjut (enhancement). Untuk itu perlu dipersiapkan suatu proses pemeliharaan yang berkesinambungan. dan ekspekstasi sebagaimana kebutuhan organisasi. Akhir tahap ini

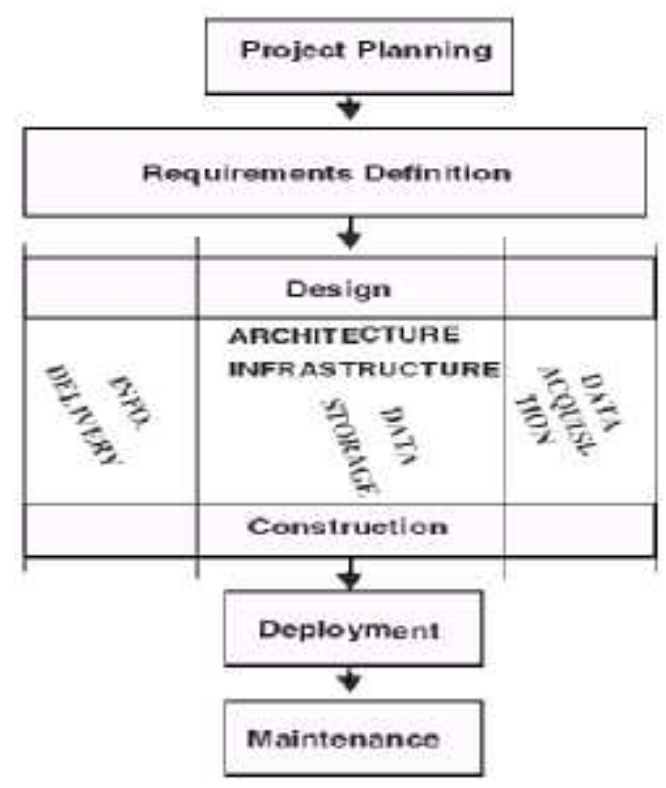

Gambar 2 Tahap Pengembangan BI

\section{PENTAHO}

Pentaho merupakan open source BI sekaligus menyediakan platform dan program untuk membangun suatu aplikasi BI. Pentaho terdiri dari banyak program komputer yang bekerja secara bersamaan dan menyediakan solusi bisnis intelijen.

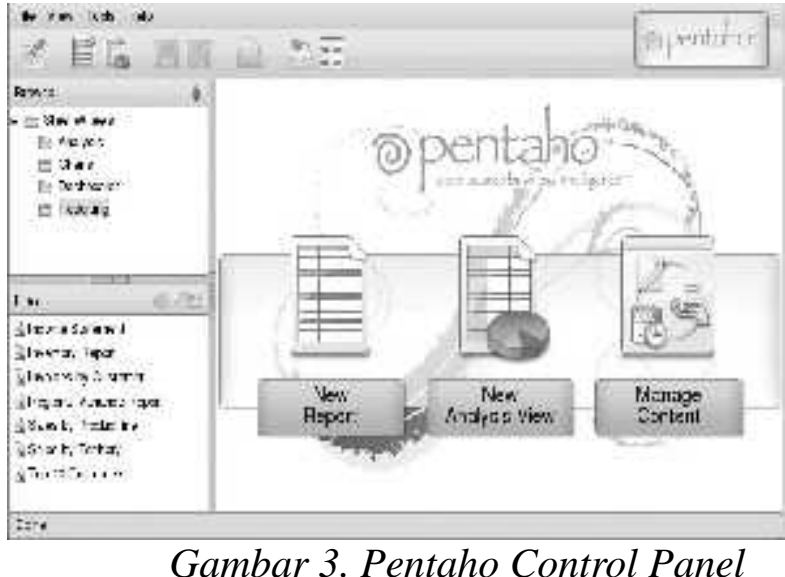

Karena terdiri dari berbagai komponen, dimana ada komponen level bawah, namun juga ada komponen yang menyediakan fungsionalitas level atas yang biasanya mengandalkan fungsionalitas yang ditawarkan oleh komponen level bawah, keseluruhan koleksi komponen dalam Pentaho dapat dilihat seperti stack, yang mana semakin tinggi levelnya maka akan semakin dekat dengan end-user

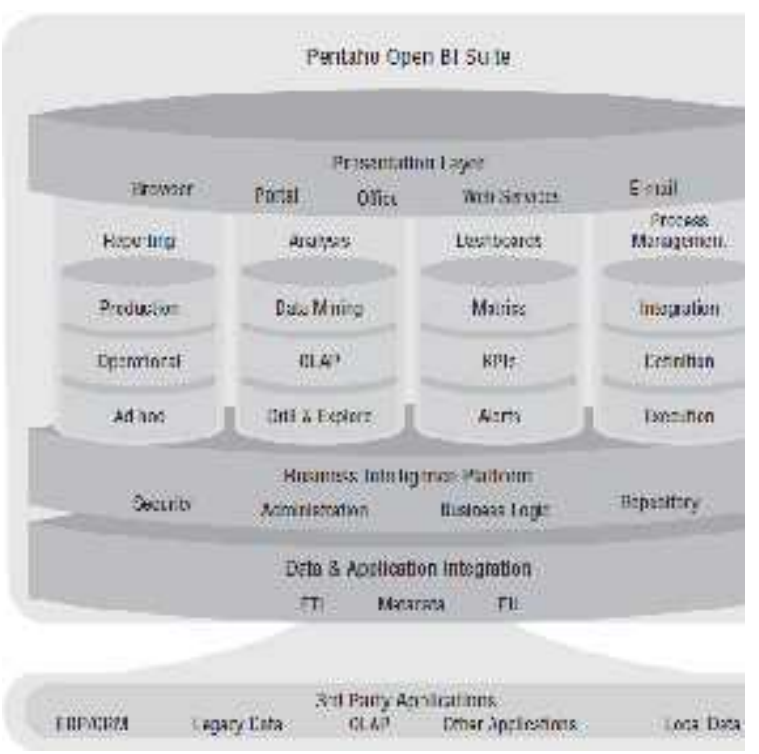

Gambar 4. Pentaho BI stack

Aplikasi-aplikasi Pentaho dikembangkan oleh Pentaho corp yang berpusat di Orlanda, Amerika Serikat. Selain sifatnya gratis dan adopsi yang semakin hari semakin luas, dukungan Pentaho bisa didapatkan dari Pentaho corp dalam bentuk Service Level 
Agreement (SLA) dan dipaketkan dalam versi Enterprise Edition yang sifatnya annual subscription atau perlu kontrak tahunan. Selain itu jika Anda tetap menggunakan community edition yang gratis, maka bisa mendapatkan support dari banyak system integrator Pentaho di seluruh dunia termasuk di Indonesia

Keseluruhan produk pembangun aplikasi BI biasa disebut dengan Pentaho BI Suite yang terdiri dari beberapa produk, dimana masing-masingnya memiliki spesifikasi fungsi tersendiri, antara lain :

a. Pentaho Reporting :

Reporting engine memungkinkan kita untuk merancang, membuat, dan mendistribusikan laporan dalam berbagai format yang sudah dikenal (HTML, PDF, dan sebagainya) dari berbagai sumber. Laporan yang dibuat dalam Pentaho didasarkan terutama di library JFreeReport, namun juga memungkinkan untuk mengintegrasikan laporan yang dibuat dengan library pelaporan eksternal seperti Jasper Laporan atau Birt.

Berikut adalah daftar database yang didukung oleh Pentaho Reporting:

AS/400, Apache Derby, Borland Interbase, ExtenDB, Firebird SQL, Generic Database (JDBC), Greenplum, Gupta SQL Base, H2, Hypersonic, DB2, Infobright, Informix, Intersystems Cache, KingbaseES, LucidDB, MS Access, MS SQL Server, MaxDB(SAP DB), MySQL, Neoview, Netezza, Oracle, Oracle RDB, Palo MOLAP Server, PostgreSQL, Remedy Action Request System, SAP R/3 System, SQLite, Sybase, SybaseIQ, Teradata, UniVerse database, Vertice, III, IV or 5.

b. Pentaho Analysis :

Mesin analisis melayani analisa secara multidimensi. Mesin analysis ini disediakan oleh Mondrian OLAP server dan JPivot library untuk navigasi dan mengeksplorasi.

c. Pentaho Dashboards :

Dashboard digunakan untuk memonitor dan menganalisa Key Performance
Indikator (KPI). Satu set alat bantu turut dimasukkan ke BI Suite dalam versi terbaru yang memungkinkan pengguna untuk membuat dashboard yang menarik, termasuk grafik, laporan, analisis pandangan, dan konten Pentaho lain, tanpa banyak usaha.

d. Pentaho Data Integration (ETL) :

Pentaho Data Integration digunakan untuk mengintegrasikan informasi yang tersebar dari berbagai sumber (aplikasi, database, file) dan membuat suatu informasi yang terintegrasi yang tersedia untuk pengguna akhir (end user). Pentaho Data Integration merupakan tool yang menjadi perhatian utama, adalah mesin yang menyediakan fungsi integrasi data tersebut.

e. Pentaho Data Mining :

Data mining menjalankan data melalui algoritma untuk memahami bisnis dan melakukan analisis prediktif. Penggunaan data mining dimungkinkan berkat adanya Weka Project.

Integrasi BI dengan Pentaho BI Suite

- BI Analysis

Bisnis Analysis merupakan visualisasi dari hasil pemetaan Data warehouse BI menjadi suatu Cube yang memiliki sudut pandang yang sama. Dalam pembuatan BI Analysis, pentaho menggunakan Pentaho Schema Workbench,

- BI Report

BI Report menyediakan 2 pilihan pelaporan untuk pengguna namun dengan konsep yang sedikit berbeda. Pelaporan pertama adalah Pentaho Solution Report, dimana isi dari laporan sudah dibentuk sedemikian rupa oleh BI Analyser dan BI Administrator, dengan mengklasifikasikan menjadi beberapa Solution yakni Sales, Purchase, Warehouse Monitoring, Customer, Finance Monitoring dan Manufacture. Pelaporan kedua merupakan report yang biasa dibentuk oleh user sesuai dengan kebutuhannya. Pelaporan ini 
disebut Ad Hoc Report, fitur ini sudah terdapat pada pentaho, namun belum sesuai dengan proses bisnis pada ERP. Implementasi yang dilakukan memiliki 2 sumber data yang menyusun report, yakni dari Pentaho Data Integration, atau proses ETL dan Data Warehouse.

- BI Scheduler

Hal yang paling krusial bagi suatu aplikasi BI adalah kevalidan data. Suatu aplikasi harus mengatur sedemikian rupa sehingga data yang didapat dan ditampilkan oleh proses ekstraksi memiliki keakuratan yang sama dengan kondisi data sumber. BI scheduling dilakukan dengan 2 metode dari 3 cara yang tersedia, yakni memakai Pentaho Scheduler dan Windows-Based System

- Bi Dashboard

Fungsionalitas dashboard hanya terdapat pada menu pentaho solution, tidak seperti report dan analysis yang menyediakan fitur lain untuk membuat konten BI analysis dan report sendiri. Dashboard lebih bersifat statis namun dengan konten analisa yang merupakan gambaran garis besar dari keseluruhan proses tertentu. Tidak semua solusi BI memiliki dashboard karena keterbatasan metode analisa yang bias diperoleh dari data yang ada. Dan juga sudah banyaknya informasi yang bisa didapatkan dari hanya diberikan untuk solusi BI yang memiliki KPI tertentu yang kompeten untuk divisualisasikan. fungsionalitas BI yang lain, sehingga dashboard

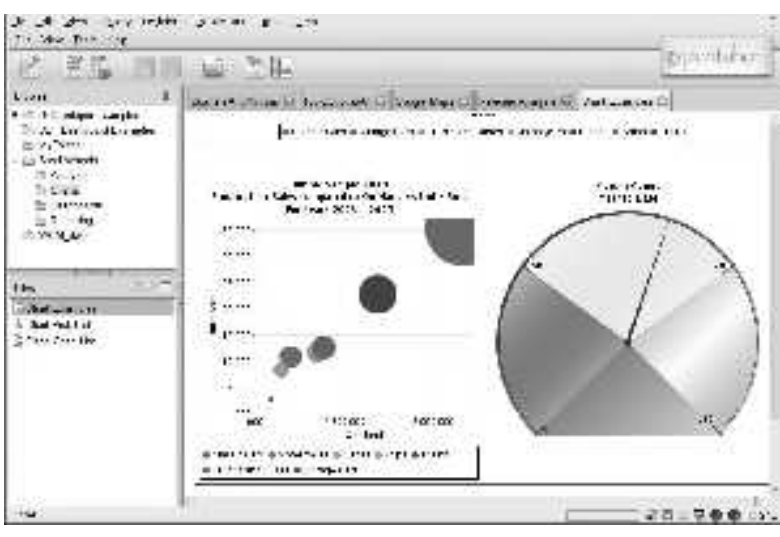

Gambar 5. Pentaho Dashboard

\section{KESIMPULAN}

Dalam mengembangkan BI terdapat tahapan-tahapan yang harus dipenuhi untuk memastikan agar pengembangan BI mencapai hasil sebagaimana yang diinginkan. Secara garis besar, tahapan meliputi : Tahap Perencanaan Proyek (Project Planning), Tahap Analisis Kebutuhan (Requirement Analysis), Tahap Desain dan Konstruksi (Design and Construction), Tahap Implementasi (Deployment), dan Tahap Pemeliharaan (Maintenance).

Disamping itu, terdapat beberapa faktor yang menjadi kunci sukses dalam pengembangan

BI, yaitu : Dukungan dan komitmen berkelanjutan dari Pimpinan, Perencanaan yang matang dan realistis, Ketersediaan data yang lengkap dan reliable.

Hingga saat ini penggunaan BI, sudah cukup banyak digunakan oleh perusahaan dan pelaku bisnis baik itu di luar maupun di dalam negeri. Memang penggunaan BI di dalam perusahaan tidaklah mudah. Membutuhkan investasi yang tidak sedikit. Namun, meskipun membutuhkan investasi yang cukup besar (dana, waktu, maupun sumber daya manusia), penerapan BI oleh perusahaan akan mampu membantu pelaku bisnis untuk memenangkan strategi dan bertahan di masa yang akan datang. Namun penggunaan BI, harus tetap diwaspadai oleh perusahaan. Jika tidak, maka investasi yang digunakan akan terbuang sia-sia. 


\section{DAFTAR PUSTAKA}

1) Brannon, Nadia (2010) . Business Intelligence and E-Discovery. Intellectual Property \& Technology Law Journal Vol. 22

2) Karina Novita Suryani \& Ir. Hira Laksmiwati Zoro, M.Sc. (2012). In press

3) Kusnawi (2005). Implementasi olap dan reporting services sebagai Bagian proses business intelligence. In Press

4) Noverino Rifai \& Kharizt Attria Gupta (2004). Perancangan e-business "Business Intelligence". In Press

5) Innarcaya Nadiar Krisanti Nasution, Riyanarto Sarno, \& Dwi Sunaryono (2007). Pembangunan aplikasi bisnis intelijen berorientasi servis pada enterprise resource planning dengan pentaho berplatform java. In Press

6) Wanda Presthus and Bendik Bygstad (2012). Business Intelligence in College: A Teaching Case with Real Life Puzzles. In press

7) D J. Power (2002). A Brief History of Decision Support Systems, DSSResources.com

8) Umeshwar Dayal, Malu Castellanos ,Alkis Simitsis dan Kevin Wilkinson.(2009). Data Integration Flows for Business Intelligence. EDBT 09

9) Tim Studi Implemetasi BI (2007). Implementasi Business Intelligence. In press 